\title{
Las casas cuartel de la Guardia Civil y de Carabineros: estudios y proyectos inéditos de González Edo en la costa malagueña
}

\author{
Daniel Pinzón-Ayala \\ Universidad de Sevilla \\ dpinzon@us.es
}

RESUMEN: Las casas cuartel de la Guardia Civil y de Carabineros se encontraban, durante el primer tercio del siglo XX, sin una definida formalización tipológica. Esto permitía una gran variedad de soluciones a ingenieros y arquitectos, preponderando las de carácter militar o con un lenguaje de corte historicista. En este periodo, José Joaquín González Edo tuvo la oportunidad de enfrentarse a este tipo de proyectos en la costa malagueña. Esto se traducirá en toda una serie de estudios y propuestas, inéditos en gran medida, en los que reflejará su visión arquitectónica contemporánea, junto con la búsqueda de una solución óptima al programa laboral-residencial de estos acuartelamientos. Se aporta así un análisis histórico y comparativo de uno de sus periodos productivos más interesantes y desconocidos, culminando en la antigua casa cuartel de la Guardia Civil en Mijas, único proyecto de nueva planta que llevó a cabo.

PALABRAS CLAVE: González Edo; Arquitectura contemporánea; Movimiento Moderno; Casa cuartel; Guardia Civil; Carabineros.

\section{The Barracks of the Civil Guard and Carabineros (Border Guards): González Edo's Unpublished Studies and Projects for the Málaga Coast}

ABSTRACT: During the first third of the 20th century, the barracks of the Civil Guard and Carabineros were not typologically defined. This offered engineers and architects a great variety of solutions in which military references on the one hand and historicist language on the other predominated. José Joaquín González Edo had the opportunity, at this time, to work on this military type of building on the coast of Málaga. This resulted in a series of studies and proposals, in which he showed his contemporary architectural vision, together with the search for an optimal solution to the hybrid program of these barracks which integrated workplace and housing. It thus provides a historical and comparative analysis of one of his most interesting and unknown periods of production, formalized in projects mostly unpublished at present. The study finally culminates with the old Civil Guard barracks in Mijas, the only new project he built.

KEYWORDS: González Edo; Contemporary Architecture; Modern Architecture; Barracks; Civil Guard; Carabineros.

Recibido: 28 de febrero de 2020 / Aceptado: 16 de junio de 2020.

\section{Introducción}

El litoral malagueño occidental es un territorio que históricamente ha estado condicionado por su carácter estratégico y un marcado despliegue militar. La necesidad de establecer una línea de vigilancia y de control llevará a la construcción de diferentes elementos arquitectónicos que puntearán la costa, acorde con las posibilidades de cada época. A pesar de las profundas transformaciones urbanísticas experimentadas en los últimos 60 años, todavía sobreviven algunas de esas arquitecturas, desde las más históricas torres atalayas, fuertes-baterías, casas fuertes, castillos; hasta la más moderna red de puestos de Carabineros, cuerpo militar creado en 1829 -desaparecido en 1940- para luchar contra el fraude fiscal y el con-

Cómo citar este artículo: PINZÓN-AYALA, Daniel, «Las casas cuartel de la Guardia Civil y de Carabineros: estudios y proyectos inéditos de González Edo en la costa malagueña", Boletín de Arte-UMA, n. ${ }^{\circ}$ 41, Departamento de Historia del Arte, Universidad de Málaga, 2020, pp. 181-193, ISSN: 0211-8483, e-ISSN: 2695-415X, DOI: http:// dx.doi.org/10.24310/BoLArte.2020.v41i.8098 
trabando. A esta institución se le sumaría, a partir de 1844 , la Guardia Civil, que de igual modo establecerá otra red de acuartelamientos -asumiendo incluso la de Carabineros a partir de 1940-, aunque con tendencia a estar asociada a los núcleos urbanos preexistentes.

Los cuarteles de Carabineros y de la Guardia Civil han experimentado una marginalidad pronunciada tanto desde el mundo investigador como del legislativo (Pinzón, 2011). Así lo demuestra la demolición sistemática de estos inmuebles cuando no su abandono total, especialmente los localizados en zonas aisladas. A esto hay que sumar que, de forma general, sus arquitecturas solían ser recicladas, precarias y de un marcado carácter doméstico, lo que no ha favorecido su puesta en valor ni la voluntad de establecer figuras de protección sobre las mismas.

De igual modo, resulta significativo que la relación que estableciera un arquitecto tan relevante para Málaga, como fue José Joaquín González Edo (1894-1989, t. 1919), con estas arquitecturas militares contemporáneas también haya quedado en el olvido y relegada dentro de los estudios monográficos sobre su obra. González Edo desarrolló gran parte de su labor profesional en la provincia, especialmente cuando lo nombran arquitecto del Catastro Urbano de Málaga en 1928. Tras obtener el título en Madrid, su formación inicial se conforma a través de una serie de estancias en Alemania, lo que le permite conocer de primera mano la arquitectura europea del momento. Este aprendizaje lo completará en España gracias a su colaboración con referentes de la época como Teodoro de Anasagasti, que supondrá, «más que la experiencia alemana, la que va a ayudar a Edo a replantearse la arquitectura [y] desarrollar una modernidad propia» (Luque, 1998: 89, 448).

El artículo a modo de homenaje y reivindicación que realizara José Seguí (1989) antes de la muerte del propio González Edo (reeditado posteriormente en 1999); el capítulo biográfico incluido en el libro de referencia La Vanguardia Imposible (Mosquera, 1990); así como la posterior tesis monográfica realizada por Francisco Luque (1998), permiten establecer puntos de referencia a la hora de estudiar a González Edo y su obra. A estas contribuciones se suman las propias publicaciones del autor que ya se encargó en vida de dar publicidad a muchas de sus obras, como así se comprueba en la revista Cortijos y Rascacielos. Ya en el siglo XXI, la donación de sus fondos, por parte de su hija, al Archivo Histórico Provincial de Málaga (AHPM), se erige como un elemento fundamental para hacer accesible la obra de este arquitecto (Barco, 2011). La exposición efectuada por el propio archivo entre noviembre de 2004 y enero de 2005 ya permitió vislumbrar la importancia de su legado, «su sentido común, su defensa del territorio malagueño, su sentido ecológico de la actividad del arquitecto y su sensibilidad temprana hacia los valores patrimoniales" (Loren, 2005: 378). Otras aproximaciones han buscado profundizar en el desarrollo de su labor en una determinada localidad (Cruces, 2010; Gallego, 1995) o en alguna de las actuaciones más significativas de su obra (Rodríguez, 2017), lo que permite seguir redescubriendo a este arquitecto y su importante legado.

Algunas obras de González Edo han merecido diferentes reconocimientos, bien con protecciones puntuales, bien recopilándose en catálogos y registros de diversa temática y arco temporal. En la base de datos Docomomo lbérico se recogen la escuela nacional de niños (19281929) y la escuela nacional de niñas Teresa Comino (1933), ambas en Villafranca de Córdoba (Córdoba), así como el edificio de viviendas Desfile del Amor (1935) en Málaga. A su vez, estas tres obras se encuentran inscritas en el Catálogo General del Patrimonio Histórico Andaluz, tal y como se recoge en la Guía Digital de la Consejería de Cultura, que a su vez registra otros tres proyectos: la casa Torres Tábora (1926-1927) en Córdoba y, ya en Málaga, el edificio de viviendas, locales comerciales y antiguo cine Actualidades (1932-1934) y la Jefatura de Obras Públicas (1941), única obra que le reconoce del periodo franquista. En cualquier caso, otras obras de esta etapa, como son el Parador Montemar, la hostería en Monte Gibralfaro o el cine Albéniz, también han sido reconocidas en otras publicaciones de relevancia (Pérez, 1986).

Esta investigación se basa en los expedientes existentes en el fondo privado de González Edo, depositado en el AHPM, y en alguna información complementaria obtenida en el archivo municipal de Mijas, en cuya localidad llevó a cabo la antigua casa cuartel de la Guardia Civil. Mediante el análisis de esta información se puede establecer cuán importante fue para González Edo sus trabajos para la Guardia Civil y Carabineros, prácticamente inéditos hasta ahora, qué planteó para estos acuartelamientos y cómo participaron en su etapa formativa inicial como arquitecto. 
Las casas cuartel de la Guardia Civil y de Carabineros: de su (in)definición a su regularización

El concepto de "casa cuartel» lo desarrolló la Guardia Civil a partir de su decreto fundacional de 13 de mayo de 1844. La idea básica era generar un tipo de acuartelamiento en el que se integraran los espacios dedicados a las dependencias oficiales - de carácter militar- con los residenciales - de carácter civil, al incluir a las familias de los guardias-. Este planteamiento no pudo traducirse en una tipología arquitectónica concreta de manera inmediata, debido a la carencia de presupuestos específicos y a la magnitud de puestos que se generaron en tan poco tiempo. Gracias a la rápida implantación territorial que se efectuó en los primeros años, comenzando en capitales de provincia y cabeceras de partidos judiciales (Martínez, 1980), se aseguró que la nueva institución resultara imprescindible desde el primer momento. Esto obligó a solucionar el acuartelamiento de tropa y familiares bien en edificios públicos cedidos, bien en inmuebles alquilados a terceros, lo que generó una red de cuarteles precaria e inestable, sometida a constantes cambios y permutas.

No será hasta las primeras décadas del siglo XX cuando se construyan las primeras casas cuartel de nueva planta. Los poderes locales, tanto públicos como privados, tomaron la iniciativa ante la incapacidad del Ministerio de la Gobernación, cartera responsable del acuartelamiento de la Guardia Civil (Pinzón, 2018). Con la proclamación de la Segunda República se darán los primeros pasos para crear un servicio técnico mediante la incorporación de una serie de arquitectos y aparejadores, que se acompañó, en 1935, con la aprobación de la normativa técnica sobre las condiciones de higiene, emplazamiento y seguridad (Pinzón, 2014). La militarización de la arquitectura de las casas cuartel que promoviera esta normativa y el hecho de que dicha regulación se desarrollara plenamente en el franquismo, marcó de manera significativa la percepción de estos acuartelamientos en el imaginario colectivo.

El Cuerpo de Carabineros, a pesar de crearse con anterioridad, no definió su tipo de acuartelamiento de una manera tan explícita como lo hiciera la Guardia Civil. Así, en diversas fuentes documentales y bibliográficas se confirma el uso de variadas nomenclaturas para las edificaciones destinadas a los Carabineros, aunque en el «Reglamento para las obras de construcción, conservación y adaptación de los cuarteles destinados al alojamiento y servicios del Cuerpo de Carabineros, la adquisición de edificios con igual destino, y la de los solares para el emplazamiento de los cuarteles que hayan de construirse», aprobado en 1927, establecía claramente la nomenclatura: "Los edificios destinados al alojamiento y servicios del Cuerpo de Carabineros que sean propiedad del Estado se denominarán "cuarteles", y "casas-cuarteles" los que, siendo de propiedad particular, se alquilen con el citado objeto». Esta diferencia, en cambio, nunca fue asumida por la Guardia Civil, que tendió a denominar a todos sus edificios como casas cuartel, independientemente de cómo se obtuvieran.

El hecho de que las competencias de los carabineros estuvieran destinadas a salvaguardar los intereses del Ministerio de Hacienda, exigía una implantación territorial muy peculiar: costas, fronteras, aduanas y puertos, fundamentalmente. También se situaron en localidades que tenían una importancia comercial relevante y exigiera un control fiscal por parte de esta institución. Esta organización periférica favorecía acuartelamientos al modo de la Guardia Civil, pero en la gran mayoría de las localizaciones resultaba imposible asumir la convivencia de carabineros y familiares, por lo que se resolvían con un programa más sencillo y, consecuentemente, con inmuebles más modestos.

Con todo, el Cuerpo de Carabineros trató de normalizar y sistematizar sus cuarteles antes que la Guardia Civil. Así, a partir de la aprobación del Real Decreto de 28 de mayo de 1902, los proyectos y las direcciones de obras de los edificios destinados a los Carabineros quedaron bajo las competencias del Cuerpo de Ingenieros, aunque el presupuesto seguía dependiendo del Ministerio de Hacienda. A partir de aquí, se procurará establecer, por un lado, las necesidades programáticas mínimas que debían satisfacer los cuarteles -acorde con la circular de 13 de enero de 1903-y, por otro, una homogeneización de estos basándose en una serie de modelos tipo -según la Real Orden de 12 de agosto de 1909-. La idea era crear cuatro anteproyectos: para capital, pueblos, playas y fronteras; como muestra de esa diversidad territorial que poseía la distribución de los carabineros en el país. No se ha podido documentar si se realizaron estos cuatro modelos, pero tal y como se recogió en el posterior reglamento de 1927, todo parece indicar que no llegaron a aplicarse: «No pudiendo sujetarse a reglas fijas la edificación de estos cuarteles, su forma, elevación, clase de 
huecos y obras que estos edificios requieran dependerán de las condiciones del terreno y del clima, según el lugar y la región en que sean construidos».

Las competencias que poseían los ingenieros militares con respecto a los edificios de Carabineros cesarían con la aprobación del Real Decreto de 24 de diciembre de 1926, para ser adjudicadas al Cuerpo de Arquitectos del propio Ministerio de Hacienda, organismo oficializado por el Real Decreto de 24 de junio de 1906. Se abría también la posibilidad de que estos proyectos recayeran en las delegaciones provinciales y en los arquitectos del catastro urbano, ofreciendo así una mayor disponibilidad de técnicos a favor del mantenimiento y mejora de la red de acuartelamientos de Carabineros. La llegada de los arquitectos se acompañó de la inmediata aprobación del ya citado Reglamento de 1927, lo que permitiría aportar otro tipo de soluciones. De todos ellos, el que se construyera para los servicios de aduana en el Puerto de Mazarrón en 1935, a cargo del arquitecto Guillermo Martínez Albadalejo, es el único reconocido con su inclusión en el registro Docomomo lbérico.

\section{Las casas cuartel de la Guardia Civil de González Edo: los ensayos tipológicos}

En su primera fase como arquitecto, González Edo realizará varios trabajos de estudio en los que mostrará hacia dónde quería encaminar su arquitectura, desde esas influencias europeas hasta la incorporación de nuevos materiales como el hormigón armado. El objetivo era aspirar a una arquitectura "que pretende ser racionalista» (Luque, 1998: 91), aunque sin lograrlo en toda su plenitud. Sí se evidencia una huida de historicismos y referencias a arquitecturas pasadas, y siempre tratando de realizar una cierta adaptación de las corrientes internacionales a las lógicas locales. Entre sus proyectos utópicos se encuentran una plaza de toros en Cádiz (1923), el frontón Euskal-Jai (1924) -junto con Mauricio Jalvo-, una ciudad deportiva (ca. 1925), una caseta para aero-club (ca. 1925) o toda una serie de estudios sobre casas cuartel de la Guardia Civil, que culminarán con el proyecto para el municipio de Mijas (1927). Además del encargo mijeño que se detallará a continuación, otras obras construidas de carácter residencial de esta primera fase más experimental serán la ya mencionada casa Tábora más un grupo de casas baratas
(1927), ambas en Córdoba, y la propuesta para el concurso de la vivienda mínima (1929).

El 31 de mayo de 1927 el consistorio de Mijas aprobó el anuncio de diversas obras para la construcción de «casas para vivienda de maestros y maestras, grupo de casas y cuartel de la Guardia Civil y ampliación del cementerio actual», por un importe total de 135000 pesetas. Este tipo de intervenciones se encuadraron en una serie de procesos de modernización de equipamientos que muchos municipios emprendieron en los años veinte, en los que resultó fundamental el apoyo del recién creado Banco de Crédito Local. El 16 de agosto de 1928 se procedió a la recepción provisional de la casa cuartel y su inauguración se anunció para el 10 de septiembre del mismo año, continuando su uso hasta principios del siglo XXI.

El acuartelamiento se ubica en la parte noroeste, zona de expansión de la localidad y con dominio sobre gran parte de la población. La vinculación urbana que se le reconoce a los proyectos de González Edo (Luque, 1998) se establece, en este caso, con la escalera de varios tramos que salva la gran diferencia de cota entre la calle y los accesos al cuartel y a las viviendas de maestros. El edificio de dos plantas se resuelve con una pieza compacta ligeramente en forma de $L$, lo que permite generar un pequeño patio trasero contra la ladera [1]. El programa se fracciona en las dos piezas que se reconocen en la planta de la casa cuartel: en una de ellas se habilita el acceso, las dependencias oficiales y una vivienda en la planta alta -seguramente para el comandante de puesto-, restando las otras cuatro viviendas del programa en la otra pieza, dos en planta inferior, dos en planta superior. Los denominados pabellones se desarrollan de manera paralela, de modo que los pasillos se sitúan medianeros: el retrete al fondo del pasillo y las tres estancias más la cocina-comedor en la misma orientación, bien al norte, bien al sur.

La imagen del acuartelamiento se caracteriza por su sencillez [2], con ciertos aires de contemporaneidad. Destaca la pieza de esquina a modo de torreón que alberga el eje ornamental del conjunto y asume la única referencia a su uso militar: el acceso resuelto con un arco sobre el que se sitúan los letreros propios de la Guardia Civil y una cornisa también arqueada, una pieza pentagonal a modo de escudo, así como el arranque del asta de la bandera.

Tras el desalojo de la casa cuartel, en los últimos años se están acometiendo las obras necesarias para reutilizar la 


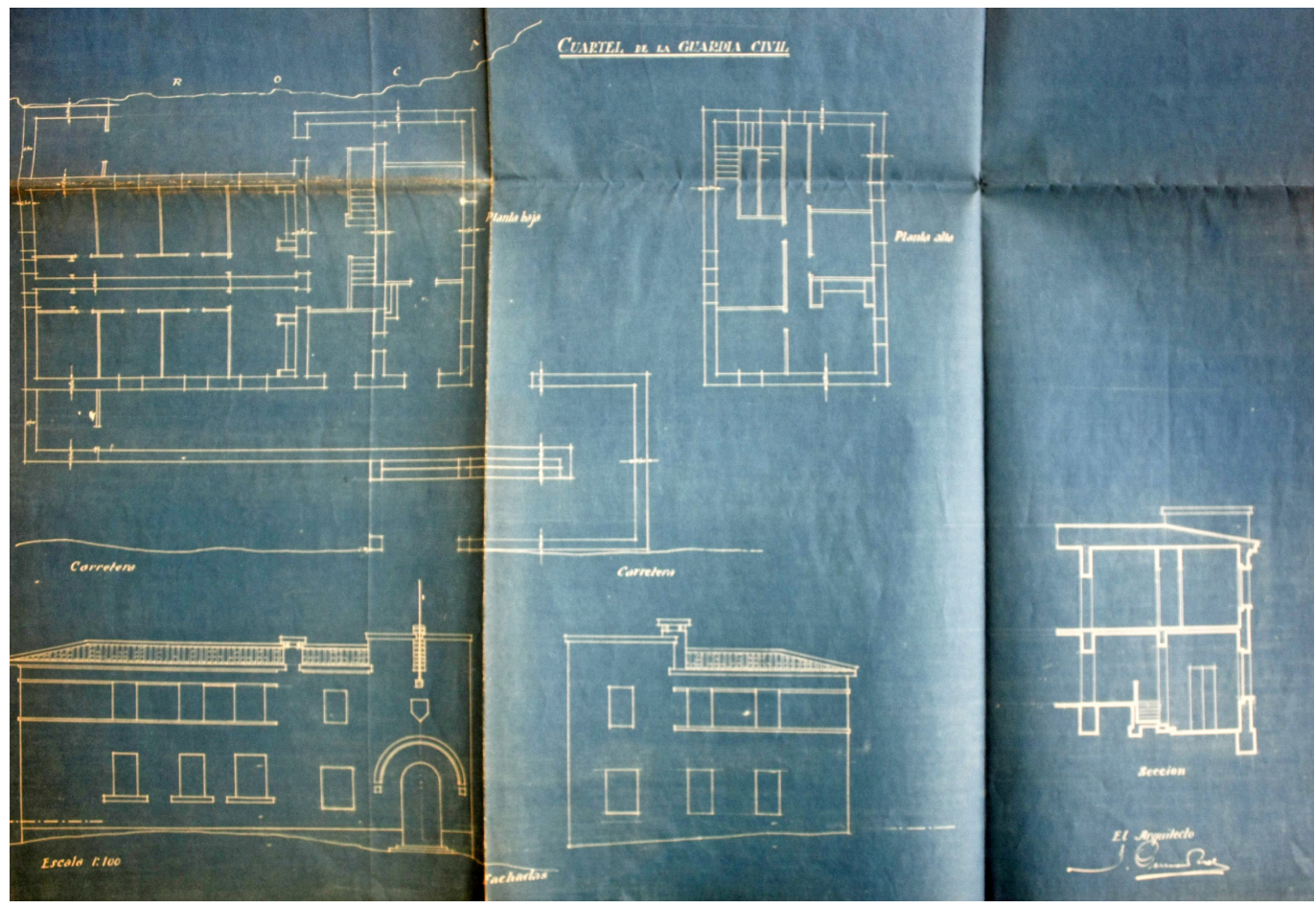

1. González Edo, J.J. (s.f.), cuartel de la Guardia Civil. Planta baja, planta alta, fachada principal, fachada este y sección. Fuente: AHPM, Fondo González Edo, Sig.: 13939

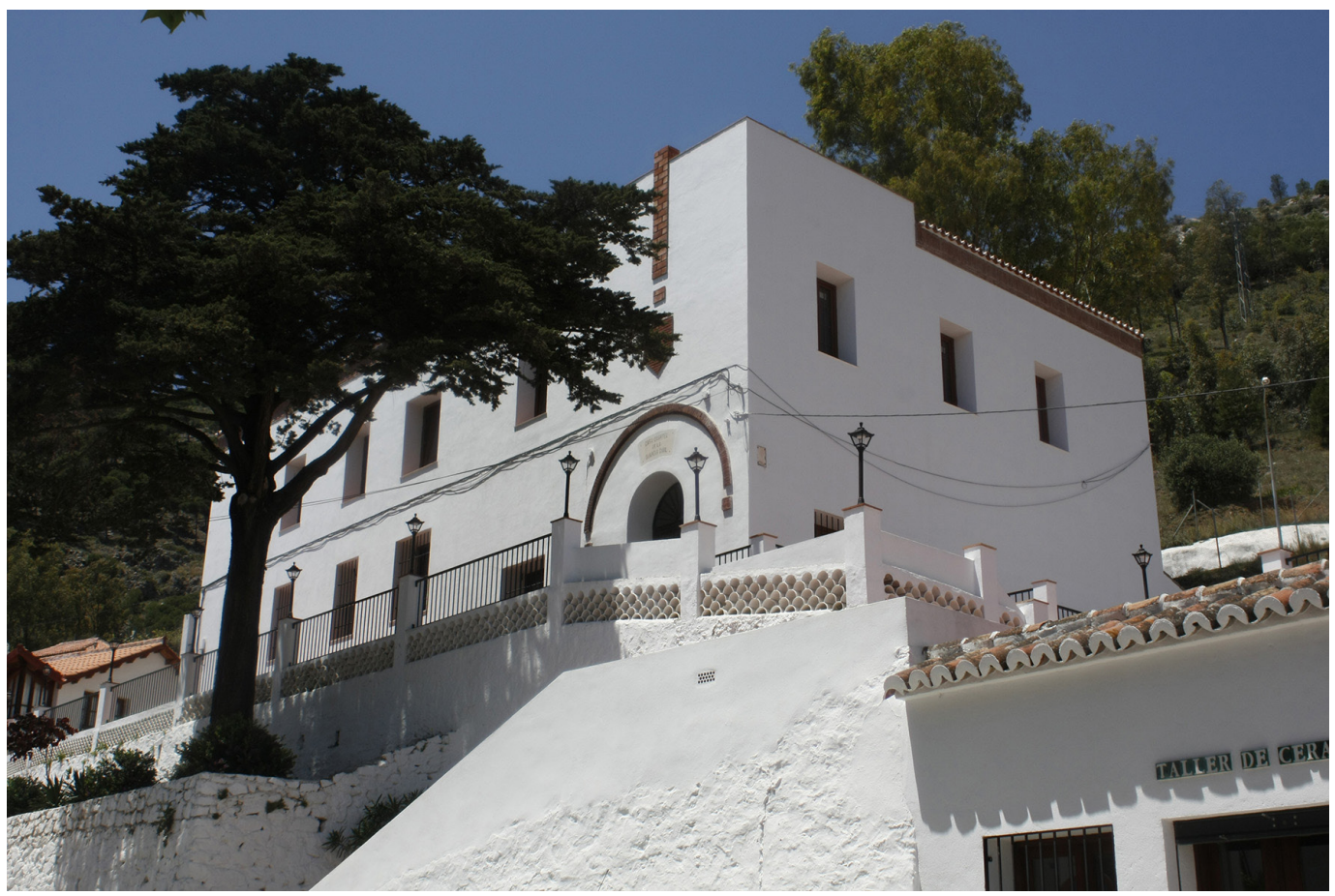

2. Antigua casa cuartel de Mijas. Estado actual (fotografía: Daniel Pinzón-Ayala, 2016) 


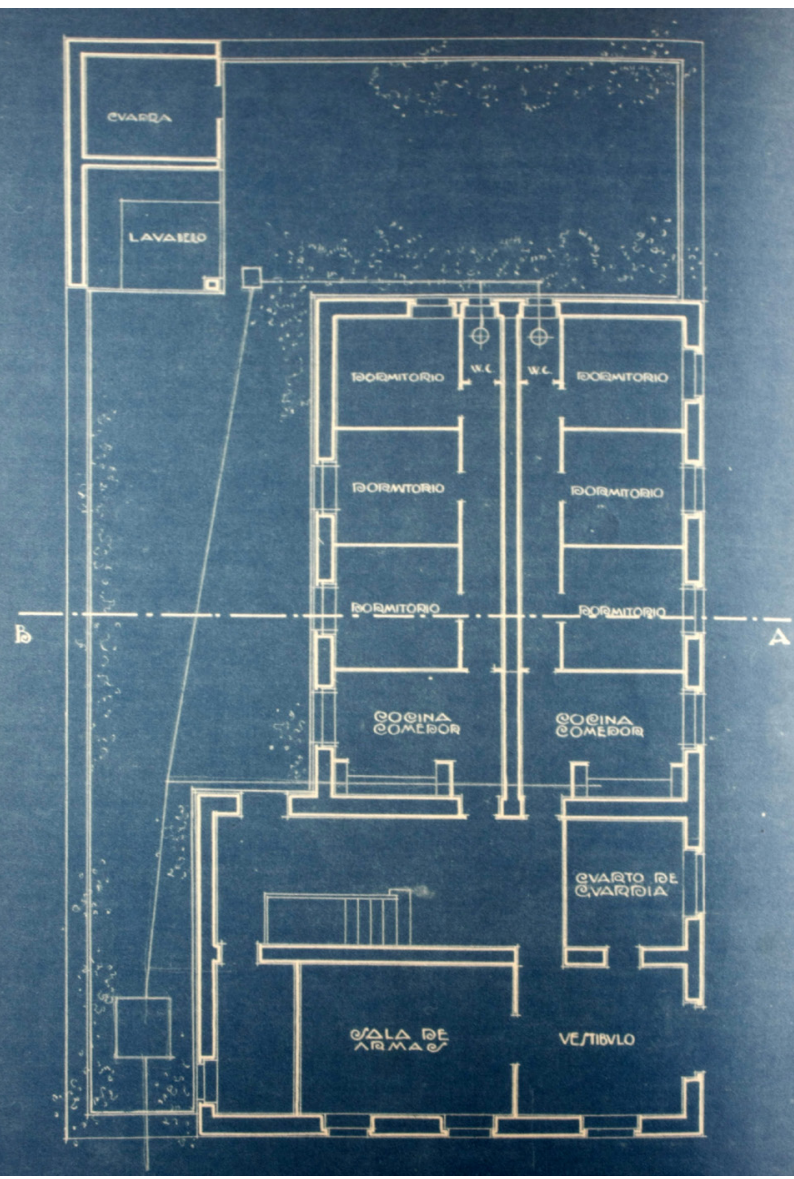

3. González Edo, J. J. (s.f.), cuartel de la Guardia Civil. Planta baja. Fuente: AHPM, Fondo González Edo, Sig.: 13938

edificación como equipamiento municipal, oscilando entre usos culturales y asistenciales, al igual que ya se hicieran con las viviendas para maestros anexas. El tipo de protección concedido en el catálogo municipal -grado B- salvaguarda al inmueble de ser demolido y recomienda la reproducción de sus condiciones constructivas primitivas. En cambio, resultan muy dudosas las intervenciones efectuadas para permitir la accesibilidad a la cota de estas edificaciones, tanto por el torreón del ascensor como por la rampa de varios tramos que conecta con la parte trasera, ya que producen un gran impacto sobre las zonas aledañas al antiguo acuartelamiento y a las viviendas de maestros.

El interés de este ejemplo aumenta cuando se entiende dentro de un proceso de análisis que realizó González Edo en torno al programa propio de una casa cuartel. Estos

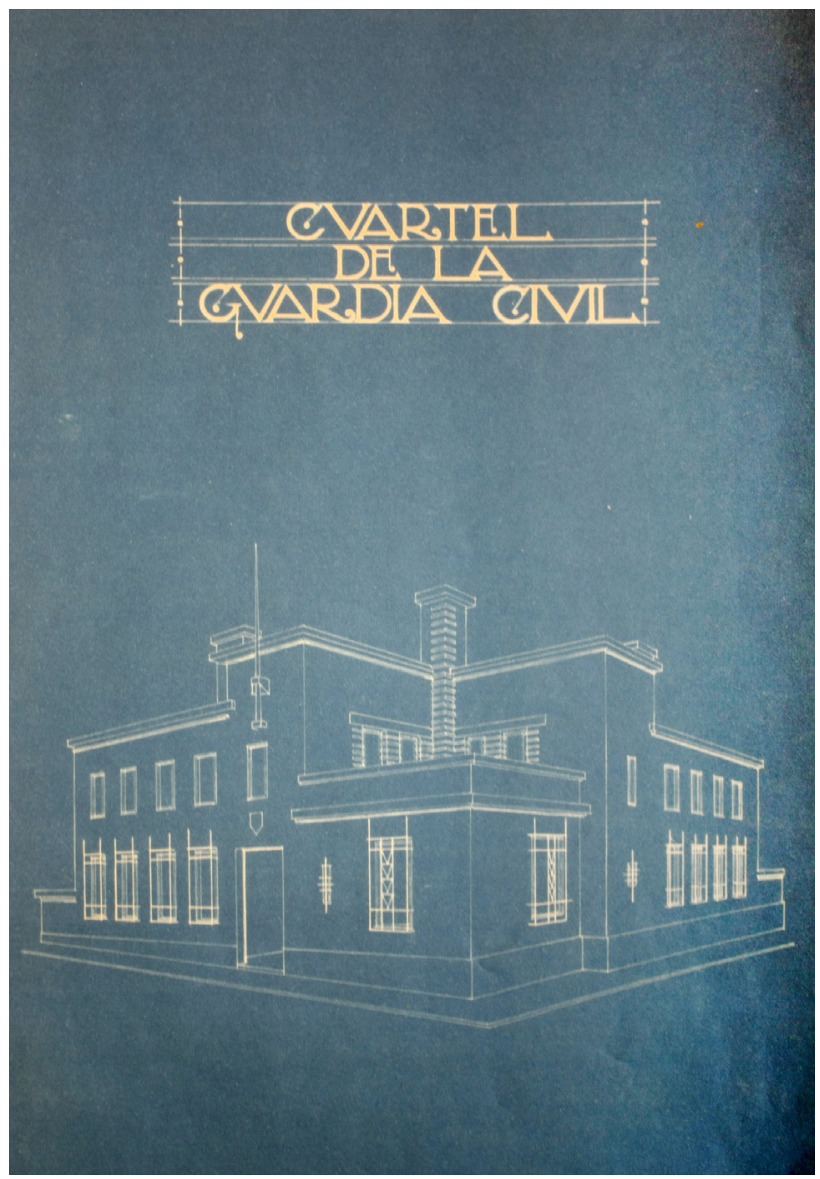

4. González Edo, J. J. (s.f.), cuartel de la Guardia Civil. Perspectiva. Fuente: AHPM, Fondo González Edo, Sig.: 13939

ejemplos han sido consultados en el fondo privado del arquitecto del AHPM, sin especificar emplazamiento ni fecha, tan solo estudios centrados exclusivamente en el objeto arquitectónico. También se tiene constancia de un proyecto de reforma en una edificación reutilizada como casa cuartel, sin datos adicionales: el inmueble es una edificación residencial configurada sobre una parcela irregular, estrecha y de gran fondo, en el que se suceden los patios de diferentes dimensiones. Intervenciones de este tipo le permitirían a González Edo conocer de primera mano la dura realidad habitacional y laboral de los miembros de la Guardia Civil.

Todo parece indicar que estos dibujos los realizó a mediados de los años veinte, de manera coetánea con el propio proyecto de Mijas. El denominador común es la ausencia de elementos militares explícitos, con un lenguaje homogéneo 


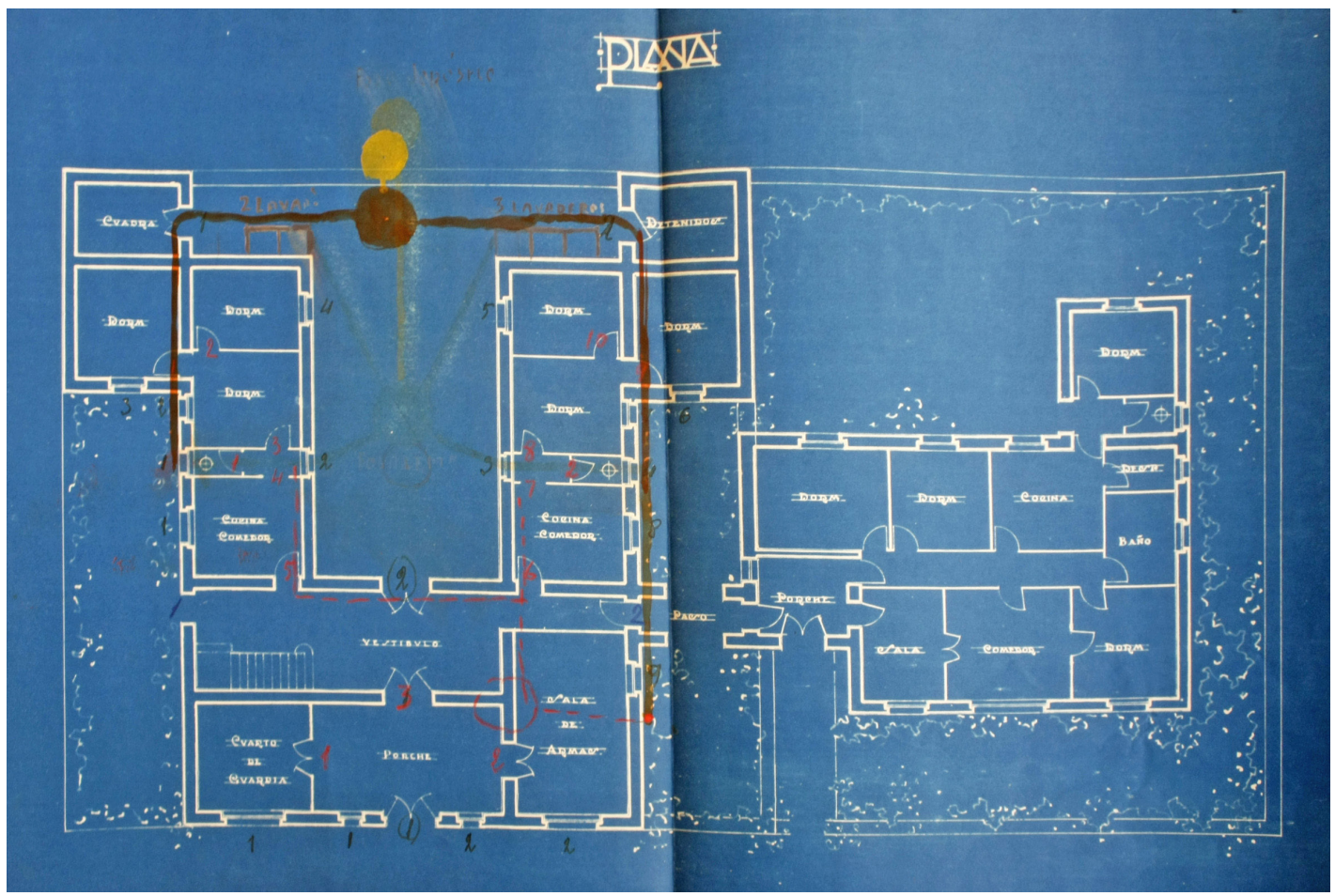

5. González Edo, J. J. (s.f.), cuartel de la Guardia Civil. Planta baja. Fuente: AHPM, Fondo González Edo, Sig.: 13938

de referencias contemporáneas, pero con diferentes propuestas tipológicas. Hasta un total de cuatro tipos se han podido documentar, siempre con un máximo de dos plantas de altura, en las que se ensayan diversas soluciones para parcelas y programas de diferentes tamaños. Dos de ellas proponen una planta en forma de $L$, otra en forma de $U$ y una última propuesta entre medianeras. En todas ellas se aprecia «un sentido de singularización volumétrica» (Luque, 1998: 431) en el que se juega con los distintos usos que componen una casa cuartel:

Las dos propuestas con planta en $L$ se diferencian por la longitud de sus brazos. La versión más corta [3] guarda muchas similitudes con el proyecto construido en Mijas ya que también se destina a cinco pabellones -con tres dormitorios, cocina-comedor y retrete-. En cambio, la mayor superficie que ofrece la parcela permite que lavaderos y cuadra puedan estar exentos en la parte trasera. En la segunda propuesta [4], el programa de pabellones aumenta a ocho. Ambos brazos se igualan -para asumir cuatro viviendas en cada uno, con el mismo programa-, aunque la parte dedicada a las dependencias oficiales, ubicadas en el ángulo, presentan una sola altura y propia alineación, lo que le permite fraccionar el volumen del conjunto y destacar la parte militar. El hecho de plantearse sobre una parcela suficientemente capaz permite de nuevo ubicar de manera aislada otros usos complementarios -cuadra, pajar, abrevadero, lavadero-, además de incorporar una hilera de árboles que muestra una cierta preocupación por acondicionar el espacio comunitario del complejo.

En la propuesta con planta en forma de $U$ [5], el programa se plantea para seis pabellones más las dependencias oficiales, que se sitúan en el frente. La peculiaridad de este caso es que la vivienda del comandante del puesto se segrega y se desarrolla de manera independiente, lo que le permite dotarla de un programa más amplio -cuatro dormitorios, sala, comedor, cocina, despensa, baño y un retrete-. En este caso, la cuadra, e incluso una pequeña celda, se incorporan a la $U$ principal, junto con los restantes cinco pabellones, que mantienen el mismo programa planteado en las tipologías anteriores.

El último ejemplo presenta un conjunto que agrupa siete parcelas entre medianeras [6], entre las que se incardi- 


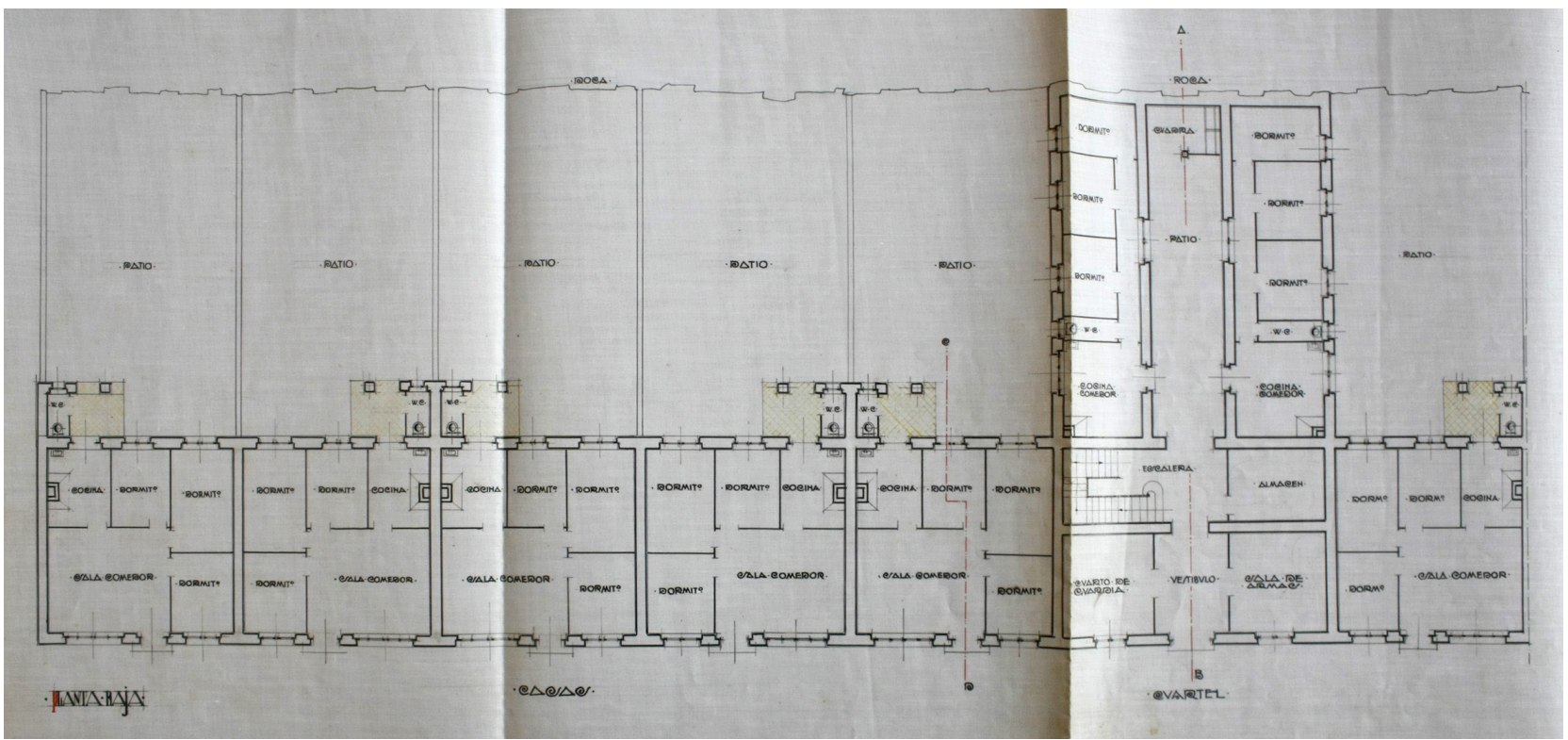

6. González Edo, J.J. (s.f.), cuartel de la Guardia Civil. Planta baja. Fuente: AHPM, Fondo González Edo, Sig.: 13938

na una dedicada al cuartel, de un ancho mayor. Todo parece indicar que las otras seis, destinadas a viviendas de una planta, no se destinan a miembros y familias de la Guardia Civil. La que se rotula como cuartel es una pieza equivalente a las anteriores, con un mayor ancho y ocupando toda la parcela hasta la medianera trasera, rotulada como rocas. Las dependencias oficiales se ubican en la fachada, distribuyendo los cinco pabellones -dos en planta baja y tres en planta alta- en torno a un estrecho patio central que permite habilitar en el fondo una pequeña cuadra. A pesar de ser la propuesta más realista con respecto al encargo del ayuntamiento de Mijas, su planteamiento no es habitual en las casas cuartel de nueva planta, ya que la dirección del cuerpo prefería que, por una cuestión de seguridad, sus acuartelamientos se presentaran exentos.

En todas estas propuestas se producen grandes similitudes con el proyecto finalmente construido en Mijas. Los programas habitacionales suelen ser los mismos, aunque en el caso mijeño no encontramos una de mayor entidad para el jefe del puesto, y se repiten las mismas intenciones volumétricas y gestos decorativos, basadas en el uso del ladrillo visto. En todos los casos se actúa con el mismo modus operandi, de modo que la parte que alberga las dependencias oficiales suele mostrarse al exterior con una volumetría pro- pia y destacada, erigiéndose como elemento de referencia dentro del conjunto.

Se ha establecido cierta relación entre estas propuestas y la Caja Postal de Otto Warner en Viena, sobre todo por el escalonamiento de los remates (Luque, 1998: 435436). También se podrían establecer ciertas comparativas con sus proyectos residenciales, aunque en este caso los pabellones se resuelven con el programa más básico, sin concesiones ninguna, algo que contrasta, por ejemplo, con su propuesta para el concurso de vivienda mínima, poco "consecuente con el tipo de vivienda unifamiliar barata" (Luque, 1998: 130). Pero es ese carácter de equipamiento público, contenido y poco dado a excesos, lo que provoca que se acerque más a la coetánea escuela para niños de Villafranca de Córdoba. Esta obra, calificada como la que «introduce en Andalucía el racionalismo moderno» (Luque, 1998: 120), se caracteriza por muchos de los elementos que ya vemos en la casa cuartel: su sentido longitudinal, la configuración de los volúmenes cúbicos con el uso de la torre como elemento destacado, el color blanco de los paramentos o el uso del ladrillo empleado con fines plásticos. Salvando las distancias obvias en cuanto a la diferencia de programas, la casa cuartel se puede encuadrar dentro la misma lógica proyectual. 


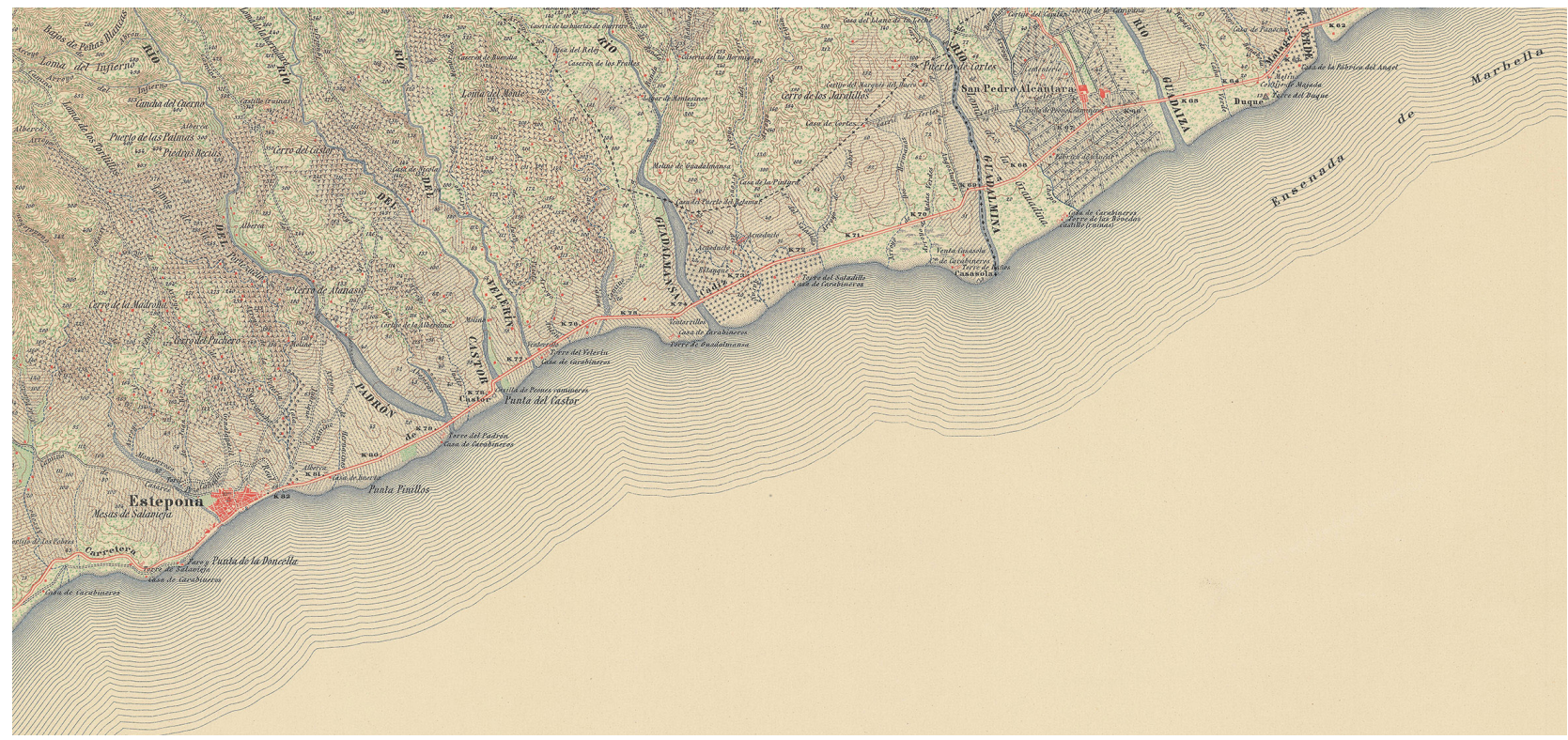

7. MTN50, escala 1:50 000, detalle hoja 1072, Estepona, 1917, 1. ${ }^{\text {a }}$ ed. Fuente: @ Instituto Geográfico Nacional

Los cuarteles de Carabineros de González Edo: hacia la dignidad laboral-habitacional

A finales de los años veinte, tras esa «arquitectura de papel» (Mosquera, 1990: 59) proyectada en su primera etapa como arquitecto, González Edo comenzará otra de carácter más maduro. En ella construirá algunos de sus edificios más reconocidos, siempre en una línea muy personal, a medio camino entre las influencias del art déco y del racionalismo y con gran atención a la «peculiaridad local» (Luque, 1998: 117). Las escuelas en Villafranca de Córdoba -dentro de su labor como arquitecto del Ministerio de Educación-; las frustradas actuaciones en Ciudad Jardín María Cristina en Almería (1930-1932), en donde aplicó un racionalismo «elementarista, de gran economía formal, reminiscente de esas formas mediterráneas» (Mosquera, 1990: $60)$, de la que solamente se llegaron a construir 22 viviendas; o la fallida ampliación del Barrio Obrero América en Málaga (1932), en la que se apuesta por una optimización de las viviendas (Reinoso, 2010); así como los reconocidos edificios de viviendas con el cine Actualidades o el conjunto residencial Desfile del Amor, consolidan su arquitectura moderna (Loren, 2008). Con todo, seguiría indagando con nuevas propuestas, como las relativas a la casa en la playa para E.N. (ca. 1933) o la casa de fin de semana en la sierra (ca. 1933).

Los trabajos que proyectara González Edo para el Cuerpo de Carabineros se desarrollaron en los años treinta. Todos ellos se efectuaron para la comandancia con sede en Estepona, que abarcaba un amplio territorio: Ronda al norte, parte de la provincia de Cádiz al oeste y el término municipal de Marbella al este. Son tres los puestos documentados en los que presentó propuestas de reformas, ampliaciones y construcciones complementarias de nueva planta: El Duque (1932-1934) y las Bóvedas (1932) en Marbella y La Chullera (1932-1934) en Estepona. Todas las localizaciones se situaban en la línea de costa, junto a antiguas torres atalaya y en zonas privilegiadas en cuanto a sus características naturales, pero despobladas y, por tanto, sometidas a unas condiciones de vida muy duras [7].

Los proyectos tienen como eje fundamental algo tan básico como la mejora de las condiciones de vida de los habitantes de estos acuartelamientos, conformados por carabineros y sus familias. A buen seguro, la habitabilidad de los inmuebles sería de una calidad pésima, tanto por las deficientes características constructivas como por la dureza del emplazamiento. Por esa razón adquiere más relevancia la presencia en los planos de árboles, terrazas y bancos, con la 


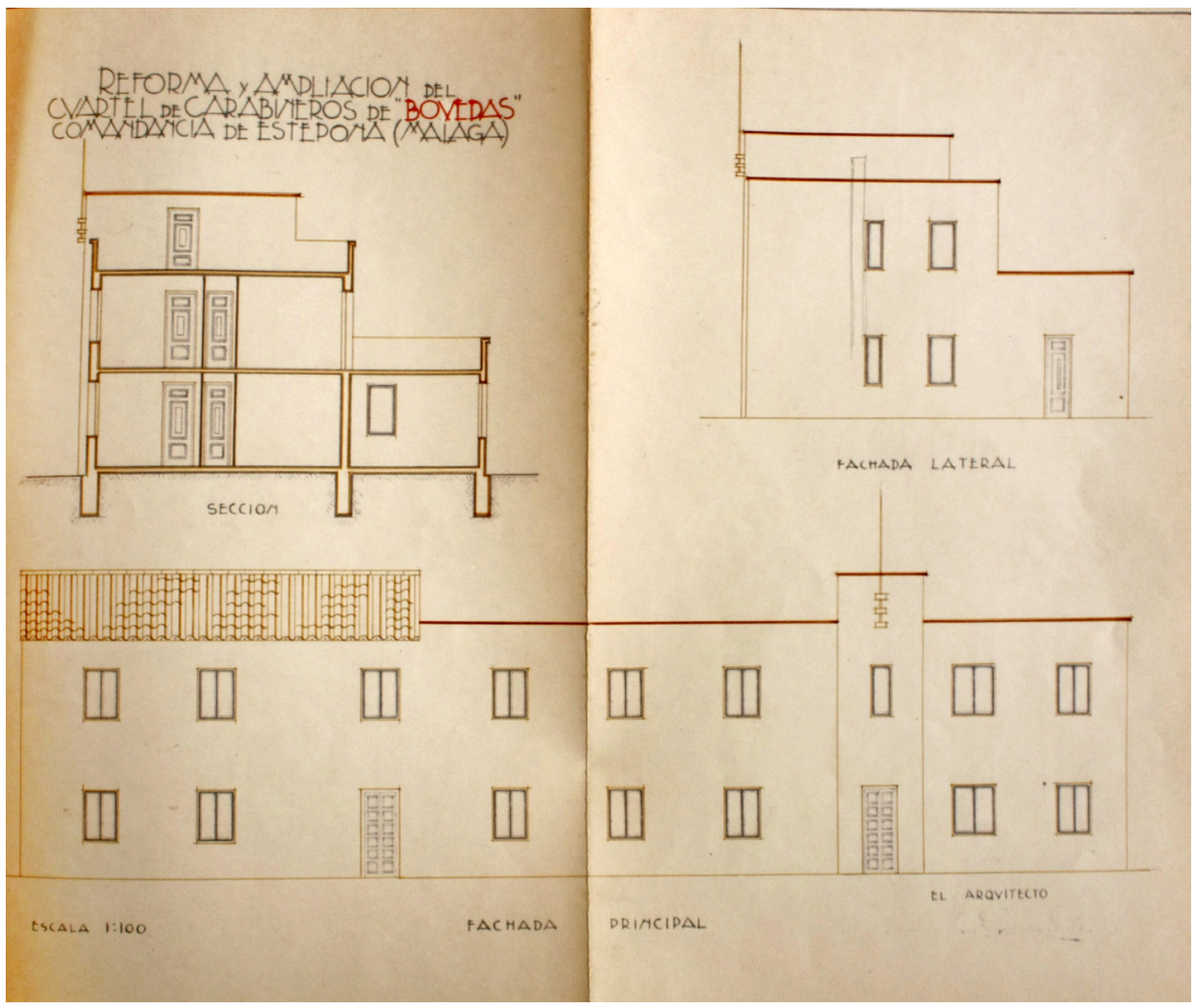

8. González Edo, J. J. (1932), proyecto de reforma y ampliación del cuartel de Carabineros "Bóvedas», Comandancia de Estepona (Málaga). Sección, fachada lateral, fachada principal. Fuente: AHPM, Fondo González Edo, Sig.: 13944 clara intención de cualificar espacios de encuentro y reunión de las diferentes familias. Toda una referencia a un concepto tan poco relevante en aquella época como era el tiempo libre $y$, especialmente, en un ambiente de comunidad castrense.

La intervención en el puesto de Bóvedas [8] partía de dos edificaciones preexistentes -cuartel viejo y cuartel nuevo-, con diferentes grados de degradación y con una total falta de adecuación, tanto para las tareas militares como para las residenciales. La actuación se centraba en acondicionar ocho viviendas, acorde con las normativas en vigor. En la misma línea se planteaba la actuación en el Duque, con tabicados y mejoras en las soluciones constructivas. Es el único inmueble del que tenemos constancia que existe en la actualidad como vivienda privada.

En el caso de Chullera [9], González Edo llega a plantear una nueva edificación como alternativa a la pastilla longitudinal que se encontraba prácticamente anexa a la torre existente. En este caso se plantea un acuartelamiento en forma de T con dos plantas, con capacidad para albergar a diez familias que debían residir en Estepona por incapa- cidad del inmueble existente. De nuevo se aprecia un cierto juego de volúmenes, tanto por la terraza presente en el eje del único acceso al complejo, como por la proyección al exterior de los retretes, rematando cada uno de los tres brazos del cuartel. En 1934 se documenta otra propuesta de cuartel [10], esta vez recurriendo a una planta con patio central, pero para siete viviendas, lo que le permite resolver todo el programa en una planta, salvo la esquina oeste que se eleva a modo de torreón. En los planos se localizan esos dibujos de vegetación, macetas y terrazas que aspiran a mejorar el entorno de estos acuartelamientos. No se tiene constancia de que ninguna de las dos propuestas se llevase finalmente a cabo.

Además, las soluciones constructivas tenían como objetivo afianzar en el tiempo las intervenciones de mejora y generar una nueva imagen. De este modo, tal y como especificaba en la propia memoria del proyecto para el puesto de Chullera de 1932, se localiza algún intento por resolver los forjados con hormigón armado, rematando así con cubierta plana, para sumar a los requerimientos propios de un 

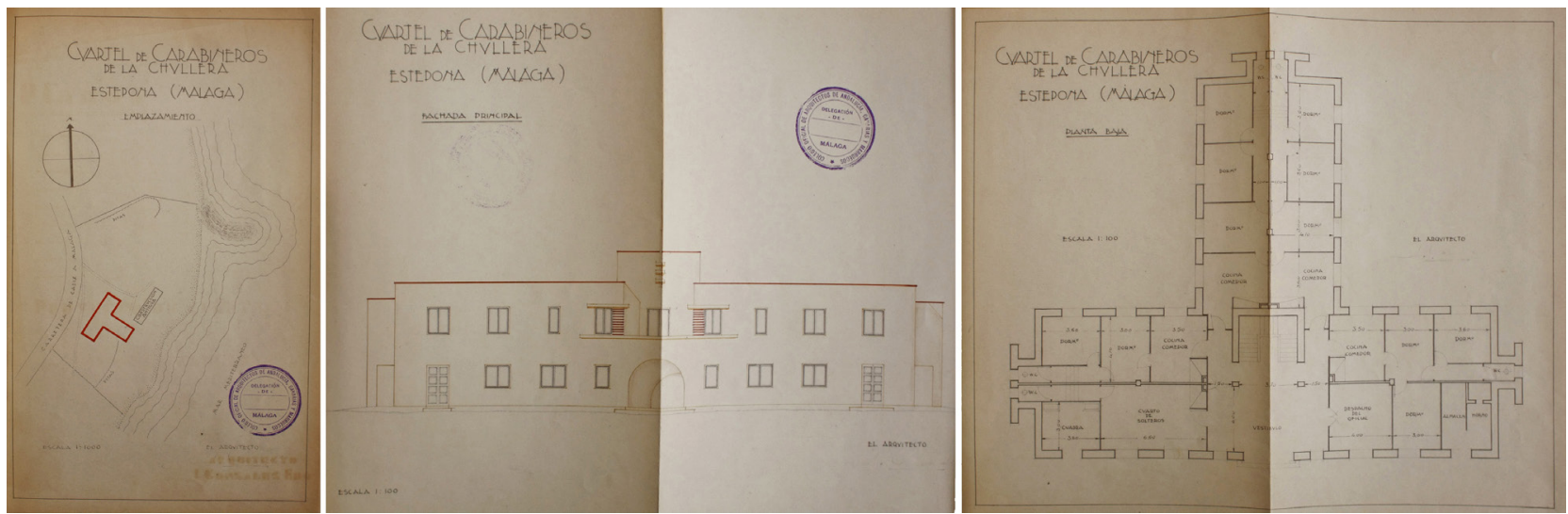

9. González Edo, J. J. (1932), proyecto de cuartel de Carabineros de la Chullera, Estepona (Málaga). Izq.: Emplazamiento. Centro: Fachada principal. Dcha.: Planta baja. Fuente: AHPM, Fondo González Edo, Sig.: 13944

acuartelamiento las soluciones constructivas características de la vanguardia europea: «hoy universalmente empleada hasta en los sitios más fríos y lluviosos como Holanda, Suecia, Alemania y Rusia, nos permite disponer de una superficie en lo alto del edificio desde donde se dominará gran extensión de terreno».

Aunque los proyectos se hubieran llevado a cabo, la precariedad de estos acuartelamientos seguiría presente, tanto por la ausencia de redes de abastecimiento de agua potable y de saneamiento, como por las distancias kilométricas a los núcleos urbanos de referencia. En cualquier caso, la mejora planteada era considerable, con aspiraciones de mejorar el día a día de sus habitantes: «en la vida lo que tiene más importancia es la convivencia, la relación de unas personas con otras» (Luque, 1998: 460).

\section{Conclusiones}

Todos estos estudios no hacen más que corroborar el camino que González Edo había trazado para su propia arquitectura: desde esa inquietud inicial por indagar nuevas

10. González Edo, J. J. (1934), proyecto de cuartel de Carabineros de la Chullera, Estepona (Málaga). Izq.: Emplazamiento. Dcha.: Fachada lateral, fachada principal, secciones y modificación. Fuente: AHPM, Fondo González Edo, Sig.: 13944
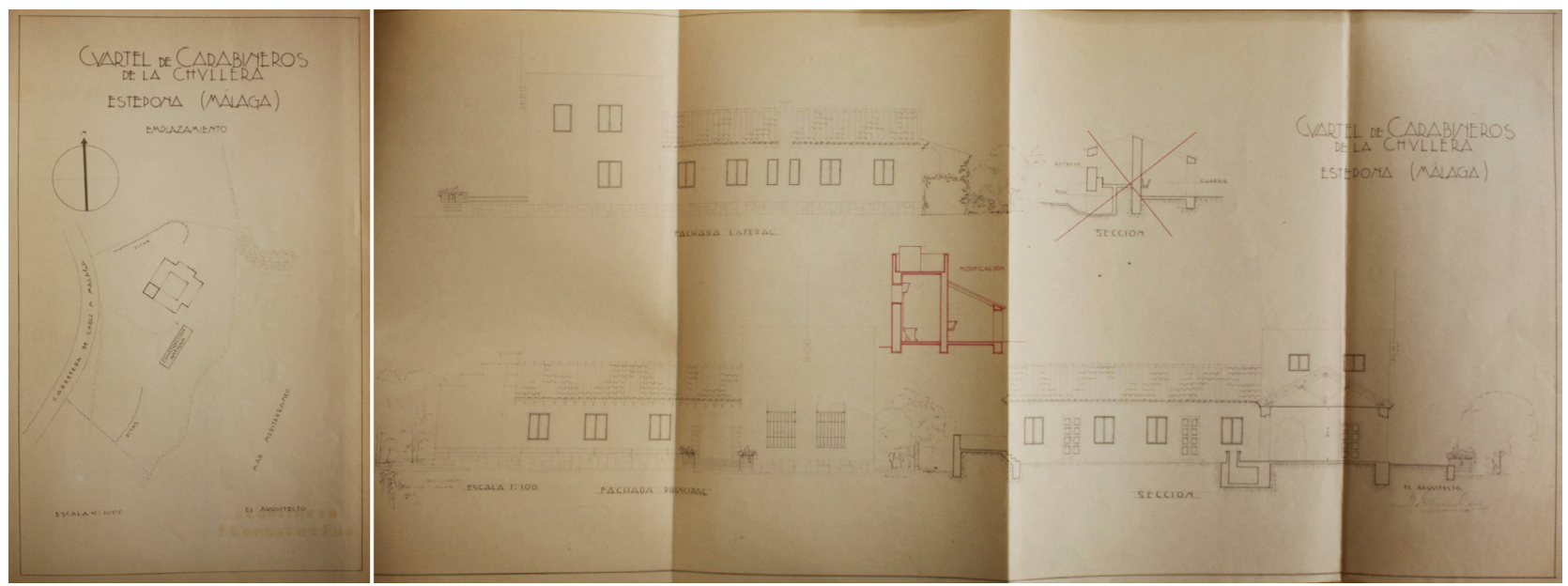
tipologías, como se hace patente en los casos de la Guardia Civil; hasta la constante preocupación por generar soluciones que favorecieran la propia vida de sus habitantes, especialmente reseñable en los puestos aislados de Carabineros. Sus proyectos son una clara muestra de la capacidad que tenían estos acuartelamientos para adaptarse a diferentes planteamientos, acorde con las corrientes arquitectónicas internacionales, manteniendo su característico programa híbrido y sin renunciar a su peculiaridad como conjuntos militares.

La casa cuartel de Mijas, ignorada dentro de la producción arquitectónica de González Edo, se inserta dentro de esa búsqueda del racionalismo de sus primeros años de producción, en la que se evidencia el conocimiento que tenía de las corrientes internacionales junto con ese interés personal por adaptarlas a las lógicas locales. El acuartelamiento, a pesar de ser la solución más contenida dentro de su producción teórica en torno a esta tipología militar, muestra, tanto con su volumetría como con el uso del ladrillo visto en combinación con los paramentos blancos, claros vínculos con los edificios escolares cordobeses. El hecho de que la casa cuartel date de 1927 y que la escuela para niños de Villafranca de Córdoba de 1928, la hace merecedora de una mayor atención desde el mundo investigador y el reconocimiento como claro antecedente de toda una serie de obras -como el edificio de viviendas con el cine Actualidades o el conjunto residencial de Desfile del Amor- que son parte del legado más icónico de la arquitectura de González Edo.

Con esta producción, tanto teórica como práctica, González Edo se erige como uno de los arquitectos que más profundizó en esta clase de edificios, sobre todo en el caso de la Guardia Civil, a cuya institución nunca estuvo adscrito. De este modo, si bien se adaptó a las particularidades que implicaban los acuartelamientos, también supo imprimirles un cierto carácter de contemporaneidad poco habitual en la época, demostrando que otras casas cuartel eran posibles.

\section{Bibliografía}

BARCO CEBRIÁN, Lorena C. (2011), «"Rescatando documentos”. La donación del archivo privado de José Joaquín González Edo en el

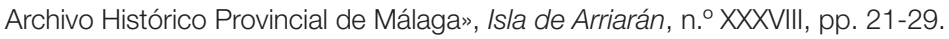

CRUCES BLANCO, Esther (2010), «José González Edo, la trayectoria vital y profesional de un arquitecto. Compromisos olvidados en Málaga (1894-1989)», Baética, n. ${ }^{\circ}$ 32, pp. 187-216.

GALLEGO ARANDA, Salvador (1995), «D. José González Edo: un primer paso hacia el racionalismo en la arquitectura melillense», Boletín de Arte, n. ${ }^{\circ} 16$, pp. 235-248.

LOREN-MÉNDEZ, Mar (2005), «La primera modernidad en España. La especificidad y las variaciones del sur», Revista Historia y Teoría de la Arquitectura, n. ${ }^{\circ}$ 6-7, pp. 377-382.

- (2008), «La modernidad española como relato de las periferias. Laboratorio arquitectónico y visiones urbanas en el alejado sur íbero», Apuntes, vol. 21, n. ${ }^{\circ}$ 2, pp. 234-251.

LUQUE GARCÍA, Francisco Rafael (1998), Arquitectura y ciudad: la obra del arquitecto D. José González Edo (tesis doctoral), Universidad de Málaga, Málaga.

MARTíNEZ RUIZ, Enrique (1980), «Ubicación geográfica inicial de la Guardia Civil», Cuadernos de Historia Moderna y Contemporánea, vol. 1, pp. 83-110.

MOSQUERA ADELL, Eduardo y PÉREZ CANO, María Teresa (1990), La Vanguardia Imposible, Consejería de Obras Públicas y Transportes, Junta de Andalucía, Sevilla.

PÉREZ ESCOLANO, Víctor; PÉREZ CANO, María Teresa; MOSQUERA ADELL, Eduardo y MORENO PÉREZ, José Ramón (1986), 50 años de Arquitectura en Andalucía, 1936-1986, Consejería de Obras Públicas y Transportes, Junta de Andalucía, Sevilla.

PINZÓN-AYALA, Daniel (2011), «La casa-cuartel de la Guardia Civil: la puesta en valor de una arquitectura marginal», Revista de Historia y Teoría de la Arquitectura, n. ${ }^{\circ}$ 10-11, pp. 107-131.

- (2014), «Las casas-cuartel de la Guardia Civil durante la II República y el Franquismo: la desconocida labor de un grupo de arquitectos», BAc Boletín Académico, n. ${ }^{\circ}$ 4, pp. 71-82. 
PINZÓN-AYALA, Daniel y LOREN-MÉNDEZ, Mar (2018), «La presencia de la Guardia Civil en los ámbitos industriales a través de sus casas cuartel: un nuevo factor en la relación entre patronal y obreros», Revista de Historia Industrial, vol. 27, n. ${ }^{\circ}$ 72, pp. 81-108.

REINOSO BELLIDO, Rafael; RUBIO DÍAZ, Alfredo y G. R. DRAGÓN, Jorge (2010), Las casas baratas de Málaga, 1911-1936, 16/dieciséis y Real Academia de Bellas Artes de San Telmo, Málaga.

RODRíGUEZ OLIVA, Pedro (2017), «El arquitecto José J. González Edo y el descubrimiento de la ciudad romana de Lacipo (Casares, Málaga)", Anuario Real Academia de Bellas Artes de San Telmo de Málaga, n. ํ 17, pp. 179-188.

SEGUÍ, José (1999), «J. González Edo: análisis de su obra», Geometría, n. 6 , pp. 62-82. 